\title{
Does photoperiodism promote hybrid zones at higher latitudes and biodiversity globally?
}

\author{
Kari Saikkonen ${ }^{1}$ \\ ${ }^{1}$ University of Turku
}

May 22, 2020

\begin{abstract}
Hybridization is accepted as a common and important evolutionary force in plants and animals. It can occur randomly or in spatially and temporarily dynamic hybrid zones where the geographic ranges of closely related species meet. Here, I propose that poleward increases in the seasonality of day length promote the maintenance of circumpolar hybrid zones at higher latitudes. Hybridization at higher latitudes should be most prevalent among species that use seasonal changes in day length to coordinate their reproductive phenology but may apply to other species as well if their fitness is dependent on species that are adapted to photoperiodic cues. Given that climate change is expanding species ranges across latitudes and creating opportunities for reproductive interactions between formerly isolated and genetically distinct populations and species, a better understanding of the evolutionary role of hybridization and its consequences for biodiversity, ecosystem functions and services is needed. At the global scale, I predict that day length-promoted circumpolar hybrid zones and consequent hybrid speciation are play significant roles in maintaining genetic admixture and species diversity on a geological time scale because species' range shifts across latitudes during the cycles of Earth's cooler and warmer periods cause recurrent isolation of and contact among species.
\end{abstract}

\section{Introduction}

Hybrid zones, the geographic regions where genetically divergent populations, varieties, subspecies or species meet and interbreed, have played a significant role in the evolutionary trajectories of all major groups of higher organisms (Anderson 1948; Anderson \& Stebbins 1954; Jenkin 1955; Remington 1968; Chevassus 1979; Barton \& Hewitt 1989; Arnold 1997; Hewitt 2001; Scriber, Page \&. Bartron 2001; Hewitt 2004; Mallet 2007; Soltis \& Soltis 2009; Hewitt 2011; Gompert, Mandeville \& Buerkle 2017; Marques, Meier \& Seehausen 2019). Taxonomic surveys and genomic data suggest that although hybridization can arise, for example, as a consequence of human actions, hybrid zones are commonly attributable to changes in species geographic ranges due to paleoclimatic periods and/or physiographic features of Earth, such as chains of mountains and islands (Anderson 1948; Anderson 1949; Weir \& Schluter 2004; Kearney 2005; Hewitt 2011; Alcaide et al. 2014; Kleindorfen et al . 2014; McFarlane \& Pemberton 2019). Consequently, hybrid zones can persist for hundreds or thousands of years, allowing gene flow between interbreeding species and genetically diverging intraspecific lineages and thus facilitating introgression, hybrid speciation, allopolyploidy and adaptive radiation of new species (Barton \& Hewitt 1985; Mallet 2005; The Marie Curie SPECIATION Network 2012; Marques, Meier \& Seehausen 2019). However, hybrid zones and hybrid species are dynamic in space and time due to natural or human-assisted environmental changes or species invasions of new habitats (Anderson 1948; Barton 1979; Hansen et al. 2000; Hewitt 2001; Hewitt 2004; Buggs 2007; Hewitt 2011). Thus, the forces driving species' range shifts can lead to repeated hybridization, rapid reproductive isolation from the same ancestral population without physical isolation and reticulated evolution, explaining the detected adaptive radiation and global biodiversity (Marcussen et al.2014; Mallet, Besansky \& Hahn 2015; Lamichhane et al. 2018; Marques, Meier \& Seehausen 2019).

Recently, climate change attributable to human influence has been recognized as among the most important 
contemporary forces driving species' distribution ranges (Parmesan \& Yohe 2003; Thuiller et al. 2005; Walter et al. 2009; Chen et al. 2011; Tewksbury, Sheldon \& Ettinger 2011; Ammunét et al. 2012; Saikkonen et al. 2012; Taylor, Larson \& Harrison 2015; Fält-Nardmann et al. 2018) and thus facilitating reproductive isolation during parapatric speciation and novel encounters between previously allopatric taxa (Alcala \& Vuilleumier 2014; Chunco 2014). Because anthropogenic climate warming in the Arctic and Antarctic has been substantially faster than the global average (Cohen et al.2014; Past Interglacials Working Group of PAGES 2016; Polvani et al. 2020), the reshuffling of species assemblages and interspecific interactions, potentially leading to adaptive hybrid speciation, will presumably be unprecedently strong at higher latitudes (Hamilton \& Miller 2015). Observational evidence from the Northern Hemisphere, where hybrids and hybrid speciation have mainly been studied, supports this hypothesis. Hybrids are commonly detected at higher latitudes and altitudes in both aquatic and terrestrial environments (Anderson 1949; Payne, Child \& Forrest 1972; Avise et al. 1990; Grant \& Grant 1992; Hewitt 2000; Jonsell 2000; Palme et al. 2004; Kelly, Whiteley \& Tallmon 2010; Heide-Jørgensen et al. 2012; Miralles 2016; Árnason \& Halldórsdóttir 2019; Saikkonen et al. 2019). For example, natural hybrids of woody and herbaceous plants (Markgraf-Dannenberg 1980; Palme et al. 2004; Hamilton \& Aitken 2013; Cronk et al. 2015; Saikkonen et al. 2019), several invertebrate taxa (Hewitt 2011), fish (Payne, Child \& Forrest 1972; Avise et al. 1990) and other vertebrates, including rodents, weasels, ungulates, bears and whales (Kelly, Whiteley \& Tallmon 2010; Hewitt 2011; Colella et al. 2018), appear to be common in arctic and subarctic regions. Furthermore, increasing evidence suggests that climate change-driven poleward shifts in species ranges potentially result in novel hybrid zones, especially at higher latitudes (Walteret al. 2009; Chunco 2014; Larson Tinghitella \& Taylor 2019). Here, I acknowledge that phylogeographic approaches have entirely ignored organisms' adaptations to day length, light intensity and spectral composition in this context.

\section{Photoperiodism, phenology of reproduction and hybrid zones}

I propose that light environment-promoted arctic hybrid zones together with species' range shifts across latitudes due to paleoclimatic oscillations play a significant role in maintaining global biodiversity on a geological time scale. To date, the high prevalence of hybridization at higher latitudes has commonly been explained by alternating series of glacial and interglacial periods during the Quaternary period that led to substantial changes in species distributions and thus recurrent isolation and contact of species and genetically diverging intraspecific lineages (Hewitt 1996; Hewitt 2001; Hewitt 2011). However, overlapping species distributions cannot alone explain hybridization, as several pre- or post-zygotic reproductive barriers such as temporal, behavioural, mechanical or gametic mismatch as well as low viability and sterility of hybrids may restrain interbreeding (Abbott 2013). Aware of the complexity of these reproductive barriers, I focus on spatially overlapping distributions and synchronous reproduction of organisms because they are the primary prerequisites for hybridization and hybrid zones.

Given that phenology is crucial for individual fitness, particularly in strongly seasonal environments, here, I emphasize the role of poleward increases in the gradient of seasonal fluctuation in day length as an accurate and consistent abiotic environmental force used by many organisms to optimally coordinate their phenological events at higher latitudes (Levin 1978; Bradshaw \& Holzapfel 2007; Bradshaw \& Holzapfel 2010; Körner \& Basler 2010; Nelson, Denlinger \& Somers 2010; Saikkonenet al. 2012). Compared to other, more variable seasonal cues, seasonal fluctuation in light intensity, duration and spectral composition is a stable, abiotic environmental factor that does not change with local or global climatic conditions, as it is governed by the tilt of Earth's axis and Earth's elliptical orbit around the sun (Nelson, Denlinger \& Somers 2010). Globally, this seasonal fluctuation determines the availability of solar energy for primary producers and the ecosystems dependent on them at both ecological and evolutionary time scales (Nelson, Denlinger \& Somers 2010; Saikkonen et al.2012). Although a changing climate may relax or strengthen temperature barriers and allow organismal range shifts, the organisms must cope with light-driven seasonality in primary production. This is particularly pronounced in ecosystems within the Arctic and Antarctic circles, which are characterized by extremes ranging from the polar day in summer to the polar night in winter.

Because virtually all life forms on Earth rely directly or indirectly on primary production, the optimal timing 
of reproduction is important at higher latitudes in temperate and polar zones, where the time window for successful reproduction is most limited due to the seasonality of solar energy (Fig. 1). In general, stabilizing selection should narrow the variance in reproductive timing in populations and increase the synchrony of reproductive phenology among populations, especially at higher latitudes (Fig. 2). This causes overlap in the timing of reproduction among genetically distinct populations and species that are otherwise compatible.

\section{Eco-evolutionary consequences}

As a global and stable abiotic ecological filter, a poleward increase in the seasonality of day length may create, promote and maintain multispecies hybrid zones at higher latitudes. Under a changing climate, synchronous reproductive timing requires the ability of both native and invading species to respond and adapt to new temperature and light environments. In general, life-history traits can evolve in response to changing selection pressures if there is sufficient genetic variability or phenotypic plasticity (Stearns 1992). Although the relative importance of phenological events for different life forms depends largely on the life-history strategies of the organisms (for example, the timing of reproduction is crucial for sexually reproducing and short-lived organisms such as annual plants (Saikkonen et al.2012)), an increasing number of observational and experimental studies have demonstrated that native and invading wild and domesticated species are able to successfully synchronize their biological events with changing temperatures or new light environments (Sakai \& Larcher 1987; Fielding et al. 1999; Bradshaw \& Holzapfel 2001; Simpson \& Dean 2002; Bonenfant et al. 2004; Dodd et al. 2005; Bradshaw \& Holzapfel 2006; Menzel et al. 2006; Niehaus \& Ydenberg 2006; Oja \& Pöysä 2007; Bradshaw \& Holzapfel 2010; Körner \& Basler 2010; Nelson, Denlinger \& Somers 2010; Zeng, Jia \& Epstein 2011; Zhaoet al. 2015; Calero et al. 2017; Taulavuori et al.2017; Black et al. 2018; Gutaker et al. 2019; Jin et al. 2019; Maeda et al. 2019). Thus, we may assume that climate changedriven range shifts leading to the spatial overlap of genetically divergent populations, varieties, subspecies or species create an opportunity for gene flow between them due to light environment-driven convergence of reproduction timing. As hybridization can occur when two or more species overlap geographically and display hierarchical spatial metapopulation structure with local populations connected by dispersal (Hanski 1999), hybrid zones can simultaneously develop among newly interconnected populations as well as multiple species (Dodd \& Afzal-Rafii 2004; Tsuda et al. 2017; Grant \& Grant 2019; Ottenburghs 2019). Here, I propose that such latitude-related hybridization can have great but largely ignored repercussions, even in ecological time, that should be taken into account in further explorations of biodiversity and how it responds to a changing climate.

Climate change-driven poleward shifts in species' ranges are commonly associated with enrichment of or decreases in and homogenization of indigenous biotas (Sala et al. 2000; Walter et al. 2009; Davis et al. 2011). Invasions by exotic species can enrich biotas, but such species can also outcompete native species and lead to species collapse when hybridized with native species (Kleindorfenet al. 2014). Consequently, native species may become locally extinct. The question, however, is whether the loss of biological species leads to the loss of genetic diversity.

Introgressive hybridization can facilitate speciation and adaptive radiation in several ways. For example, introgressive hybridization (1) can facilitate gene flow across the hybrid zone, (2) increase genetic variation and alter the genetic correlations among traits, (3) reshuffle DNA into new combinations and thus facilitate the operation of genetic material in novel cellular and ontogenetic contexts, and (4) alter ecologically important phenotypic traits (Grant \& Grant 1992; Grant \& Grant 1004; Mallet, Besansky \& Hahn 2015; Gompert, Mandeville \& Buerkle 2017; Gutaker et al. 2019; Marques, Meier \& Seehausen 2019). Thus, I argue that future studies should take hybrids into account as "poorly differentiated way-stations in a continuous hierarchy of biodiversity (Mallet 2005)" and aim to capture the breadth of relevant genetic diversity, structure and dynamic features of mosaics of genotype frequencies in populations and supposed species rather than focusing only on species diversity. To this end, hybridization challenges the biological species concept. However, if we accept recurrent hybridization and consequent introgression as the process increasing genetic variation during speciation, we may assume that the promotion of hybrid zones by poleward increases in the seasonality of day length will result in phylogenetic nets with genotypic clusters rather than classic bifurcating trees 
comprising clearly distinct species (Fig. 3).

However, the importance of light environment-driven hybrid evolution can be assumed to vary among organismal groups. Although nearly all life forms respond to light, hybridization at higher latitudes should be most prevalent among primary producer species because they are directly and highly dependent on the sun as an energy source. In concordance with this hypothesis, hybrids are commonly found in many subarctic and arctic plants (Johnsson 1949; Dugle 1966; Hultén 1971; Markgraf-Dannenberg 1980; Bassman et al. 1982; Keinänen et al. 1999; Palmeet al. 2004; Cronk et al. 2015; Saikkonen et al. 2019). Many of these plants are trees, suggesting that introgressive hybridization provides the genetic variation necessary to adapt to harsh environmental conditions, particularly in perennial species with a long life expectancy and high age at maturity. For example, hybridization has played an important role in the evolution of birches (Betulaspp.), oaks (Quercus spp.), spruces (Picea spp.) and willows (Salix spp.), most of which have economic importance in forestry (Palme et al. 2004, Cronk et al. 2015). In addition, photoperiodic adaptation and adaptability to new light environments require that the species' photoperiodic life-history traits are heritable (Bradshaw \& Holzapfel 2007). Thus, predicting species' range shifts across latitudes and their probability of hybridizing with other compatible lineages and/or species requires an understanding of the relative importance of phenotypic plasticity and the genetic regulation of traits determining their timing of reproduction, as well as the genetic mechanisms that may promote or constrain the adaptive evolution of the species and their hybrids. The eco-evolutionary consequences can be strikingly different depending on whether the timing of reproduction is phenotypically plastic, genetically determined and/or epigenetically modulated, even if the populations appear to be similarly adapted to the environment. This is because phenotypically plastic individuals with low genetic variation may perform as well as individuals reproducing at the optimal time in a population with sufficient genetic variability.

Hybridization may also play an equally important role at other trophic levels at higher latitudes. In addition to plants, many invertebrates and vertebrates (Bradshaw \& Holzapfel 2007; Bradshaw \& Holzapfel 2010) display photoperiodic adaptations. For example, the North American mosquito (Wyeomyia smithii), the European blackcap (Sylvia atricapilla), the Yukon red squirrel (Tamiasciurus hudsonicus ), the European great tit (Parus major), the European barn swallow (Hirundo rustica) and fruit flies (Drosophila spp. ) have genetically based and adaptive photoperiodic responses to climate change (Berthold et al. 1992; Hard, Bradshaw \& Holzapfel 1993; Bradshaw \& Holzapfel 2001; Bradshaw, Quebodeaux \& Holzapfel 2003; Réale et al. 2003; Nussey et al. 2005; Schmidt et al. 2005; Bradshaw \& Holzapfel 2006; Tauber et al. 2007; Bradshaw \& Holzapfel 2008). Furthermore, adaptive responses to novel light environments are likely to evolve in other species if their fitness is highly dependent on species that are adapted to photoperiodic cues. Such cascading effects can be reinforced by hybridization-driven breakdown in resistance to pests (Morrow \& Fox 1989; Whitham 1989).

\section{The Arctic vs. Antarctica}

Unequivocal evidence shows that polar glaciers are retreating, sea level is rising and habitats of arctic species are shifting poleward due to climate change. Consequently, the distribution of many species will shift to higher latitudes and altitudes. However, I propose that the consequences of climate change for biotas will differ between the Northern and Southern Hemispheres for the following two reasons.

First, the geomorphologies of the polar regions are fundamentally different. Although the land areas within the Arctic and Antarctic circles are nearly equal, the distributions of land and sea are geographically almost the opposite (Fig. 4). The Arctic Basin is a semi-enclosed ocean surrounded by land masses. Presently, most of the Arctic Ocean is covered in floating sea ice nearly year round. Thus, the Arctic will become an oceanic realm and a melting pot (Kelly, Whiteley \& Tallmon 2010), especially for compatible marine species, when the polar glaciers disappear (Fig. 4). Although the predictions of global climate models vary, most of them suggest that the Arctic Ocean will be ice free before the end of the century (Thackeray \& Hall 2019). In contrast, Antarctica is the world's fifth-largest continent and is surrounded by an ocean, and it will provide the last suitable habitat for terrestrial species adapted to cold. 
Second, the Arctic climate is substantially milder than the Antarctic climate because of the warming influence of the Arctic Ocean underneath the ice sheath. As climate change is faster and the ice-free land area is greater in the Arctic than in Antarctica, it is understandable that the majority of observational evidence of species range shifts and hybridization comes from the Northern Hemisphere.

Furthermore, I propose that circumpolar species invasions will be common, particularly in the Northern Hemisphere, because comparable climate zones are present at higher latitudes in Western Europe compared with North America owing to Gulf Stream effects (Saikkonen et al.2012)(Fig. 4). Consequently, the loss of arctic habitats probably will affect northernmost Europe first and induce many arctic species to move to subarctic and arctic regions of Russia and North America. On a geological time scale, the resilience, maintenance and regeneration of global biodiversity largely depend on the dispersal ability of compatible organisms being sufficient to retain the genetic variation required to cope with changing selection pressures and to diversify. Myriads of microbes, plants and animals have been shown to be capable of moving into new areas worldwide (Schumann 1998; Hulme 2009; Richardson \& Rejmánek 2011; van Kleunen et al. 2015; Warren et al.2015; Saikkonen et al. 2019), but the role of circumpolar hybrid zones and consequent hybrid speciation in maintaining the genetic admixture needed to support adaptive radiation and biological diversity on a geological time scale has been ignored.

\section{Future perspectives/Consequences}

The jeopardy faced by Earth's life-supporting biological processes due to rapidly accelerating climate changedriven losses of genetic, species and habitat diversity is undeniably one of the largest present-day global challenges. Alongside direct human actions causing species extinctions, anthropogenic climate change is recognized to shrink habitats, particularly those of arctic species because the Arctic is warming more than twice as fast as the global average (Cohen et al. 2014). Here, I emphasize the role of photoperiodic cues in providing accurate and consistent signals for species to optimally coordinate their timing of reproduction and propose that as a result, overlapping reproduction promotes the maintenance of circumpolar hybrid zones at higher latitudes. Because hybridization can increase the genetic variation in lineages and facilitate rapid speciation and adaptive radiation, especially if involving ancestral variation derived from hybridization (Grant \& Grant 1992; Grant \& Grant 1994; Mallet 2005; Mallet 2007; Gompert, Mandeville \& Buerkle 2017; Grant \& Grant 2019; Marques, Meier \& Seehausen 2019), circumpolar hybrid zones together with recurrent cross-latitudinal migration of species plays an important role in maintaining global biodiversity on a geological time scale (Fig. 5).

Hybridization has been known and discussed at least since the time of Linnaeus (Mallet 2005). After decades of silence, the importance of hybridization resurfaced in the context of recurrent glacial periods promoting genome reorganization when Hewitt published his paper "Some genetic consequences of ice ages, and their role in divergence and speciation (Hewitt 1996)" in 1996. Since then, advances in molecular microbiology have revolutionized the ability of scientists to study genetic diversity and hybridization, leading to an extreme abundance of related literature. A Web of Science search (May 20, 2020) using "Hybrid* AND speciation" as topic keywords yielded 7,880 published references, with 64 of the papers ranked as "highly cited". More than $94 \%$ of the papers were published after 1996. To date, genetic variation and gene combinations resulting from hybridization have been detected in at least $10 \%$ and $25 \%$ of animal and plant species, respectively (Mallet 2005). However, much of the scientific and particularly public discussion of biodiversity loss has been, and still is, species centric, and we are still just beginning to understand how hybrid speciation affects the genetic diversity necessary to adapt to new or changing selection pressures (Wilson 1988; Rhymer \& Simberloff 1996; Cardinale et al. 2012; Perino et al. 2019; Sánchez-Bayo \& Wyckhuys 2019). Here I argue that to tackle one of the foremost global challenges of our time, climate change-driven biodiversity loss, we urgently need a thorough understanding of the elements of biological diversity beyond the species level and assurance that sufficient genetic potential will remain (Grant \& Grant 2019; Razgour et al. 2019) to support the associated ecosystem functions and services on Earth in the future. To test the hypothesis that photoperiodism-promoted hybrid zones at higher latitudes play role in maintaining biodiversity globally requires interdisciplinary research approaches. These should combine (1) molecular genetics to trace evidence 
for ancient and recent hybridization (Marcussen et al. 2014; Xiang et al. 2015; Jordan et al. 2018), and (2) empirical ecology utilizing e.g. reciprocal transplant experiments across latitudes (Leinonen et al. 2019) and (3) crossbreeding experiments.

\section{Acknowledgements}

I thank M. Helander and I. Saloniemi for invaluable comments on the manuscript and O. Saikkonen for preparing the world climate maps. This work was supported by the Academy of Finland (project numbers 295976 and 326226).

\section{References}

Abbott, R. (2013). Hybridization and speciation. J. Evol. Biol. , 26, 229-246.

Alcaide, M., Scordato, E.S.C., Price, T.D. \& Irwin, D.E. (2014). Genomic divergence in a ring species complex. Nature , 511, 83-85.

Alcala, N. \& Vuilleumier, S. (2014). Turnover and accumulation of genetic diversity across large time-scale cycles of isolation and connection of populations. Proc. R. Soc. B , 281, 20141369.

Ammunét, T., Kaukoranta, T., Saikkonen, K., Repo, T. \& Klemola, T. (2012). Invasive and resident defoliators in a changing climate: cold tolerance and predictions concerning extreme winter cold as a range limiting factor. Ecol. Entomol., 37, 212-220.

Anderson, E. (1948). Hybridization of the habitat. Evolution , 2, 1-9.

Anderson, E. (1949). Introgressive hybridization . Wiley, New York, USA.

Anderson, E. \& Jr. Stebbins, G.L. (1954). Hybridization as an evolutionary stimulus. Evolution, 8, 378-388.

Árnason, E. \& Halldórsdóttir, K. (2019). Codweb: Whole-genome sequencing uncovers extensive reticulations fueling adaptation among Atlantic, Arctic, and Pacific gadids. Sci. Advances, 5, eaat8788.

Arnold, M.L. (1997). Natural hybridization and evolution . Oxford University Press, Inc. New York, USA.

Avise, J. C., Nelson, W.S., Arnold, J., Koehn, R.K., Williams, G.C. \& Thorsteinsson, V. (1990). The evolutionary genetic status of Icelandic eels. Evolution , 44,1254-1262.

Barton, N.H. (1979). The dynamics of hybrid zones. Heredity , 43, 341-359.

Barton, N.H. \& Hewitt, G.M. (1985). Analysis of hybrid zones.Annu. Rev. Ecol. Syst., 16, 113-148.

Barton, N.H. \& Hewitt, G.M. (1989). Adaptation, speciation and hybrid zones. Nature, 341, 497-503.

Bassman, J., Myers, W., Dickmann, D., \& Wilson, L. (1982). Effects of simulated insect damage on early growth of nursery-grown hybrid poplars in northern Wisconsin. Can. J. For. Res. , 12, 1-9.

Berthold, P., Helbig, A.J., Mohr, G., \& Querner, U., (1992). Rapid microevolution of migratory behaviour in a wild bird species. Nature, 360, 668-670.

Black, C., Collen, B., Lunn, D., Filby, D., Winnard, S., \& Hart, T. (2018). Time-lapse cameras reveal latitude and season influence breeding phenology durations in penguins. Ecol. Evol. , 8, 8286-8296.

Bonenfant, C., Loe, L.E., Mysterud, A., Langvatn, R., Stenseth, N.C., Gaillard, J.-M. et al. (2004). Multiple causes of secual segregation in European red deer: enlightments from varying breeding phenology at high and low latitude. Proc. R. Soc. Lond. B , 271, 883-892.

Bradshaw, W.E. \& Holzapfel, C.M. (2001). Genetic shift in photoperiodic response correlated with global warming. Proc. Natl Acad. Sci. USA , 98, 14509-14511.

Bradshaw, W.E. \& Holzapfel, C.M. (2006). Evolutionary response to rapid climate change. Science , 312, $1477-1478$. 
Bradshaw, W.E. \& Holzapfel, C.M. (2007). Evolution of animal photoperiodism. Annu. Rev. Ecol. Evol. Syst. , 38, 1-25.

Bradshaw, W.E. \& Holzapfel, C.M. (2008). Genetic response to rapid climate change: It's seasonal timing that matters. Mol. Ecol. , 17, 157-166.

Bradshaw, W.E. \& Holzapfel, C.M. (2010). Light, time, and the physiology of biotic response to rapid climate change in animals.Annu. Rev. Physiol. , 72, 147-166.

Bradshaw, W.E., Quebodeaux, M.C., \& Holzapfel, C.M. (2003). Ciracadian rhythmicity and photoperiodism in the pitcher-plant mosquito: Adaptive response to the photic environment or correlated response to the seasonal environment? Am. Nat. , 161, 735-378.

Buggs, R.J.A. (2007). Empirical study of hybrid zone movement.Heredity , 99, 301-312.

Calero, S., Joye, D.A., Rey-Boissezon, A., \& Rodrigo, M.A. (2017). Time and heat for sexual reproduction: comparing the phenology of Chara hispida of two populations at different latitudes. Aquat. Bot., 136, 71-81.

Cardinale, B.J., Duffy, J.E., Gonzalez, A., Hooper, D.U., Perrings, C., Venail, P. et al. (2012). Biodiversity loss and its impact on humanity. Nature , 486, 59-61

Chen, I.C., Hill, J.K., Ohlemüller, R., Roy, D.B. \& Thomas, C.D. (2011). Rapid range shifts of species associated with high levels of climate warming. Science, 333, 1024-1026.

Chevassus, B. (1979). Hybridization in salmonids: results and perspectives. Aquaculture, 17, 113-128.

Chunco, A.J. (2014). Hybridization in a warmer world. Ecol. Evol. , 4, 2019-2031.

Cohen, J., Screen, J.A., Furtado, J.C., Barlow, M., Whittleston, D., Coumou, D. et al. (2014). Recent Arctic amplification and extreme mid-latitude weather. Nat. Geosci. , 7, 627-637.

Colella, J.P., Lan, T., Schuster, S.C., Talbot, S.L., Cook, J.A. \& Lindqvist, C. (2018). Whole-genome analysis of Mustela ermineafinds that pulsed hybridization impacts evolution at high latitudes.Comm. Biol. , 1, 51.

Cronk, Q., Ruzzier, E., Belyaeva, I. \& Percy, D. (2015). Salixtransect of Europe: latitudinal patterns in willow diverstity from Greece to arctic Norway. Biodiversity Dat Journal , 3, e6258.

Davis, M.A., Chew, M.K., Hobbs, R.J., Lugo, A.E., Ewel, J.J., Vermeij, G.J. et al. (2011). Don’t judge species on their origins. Nature , 474, 153-154.

Dodd, R.S. \& Afzal-Rafii, Z. (2004). Selection and dispersal in a multispecies oak hybrid zone. Evolution 58, 261-269.

Dodd, A.N., Salathia, N.,. Hall, A, Kévei, E., Tóth, R., Nagy, F.et al. (2005). Plant circadian clocks increase photosynthesis, growth, survival, and competitive advantage. Science , 309, 630-633.

Dugle, J.R. (1966). A taxonomic study of western Canadian species in the genus Betula . Can. J. Bot ., 44, 929-1007.

Fielding, C.A., Whittaker, J.B., Butterfield, J.E.L. \& Coulson, J.C. (1999). Predicting responses to climate change: the effect of altitude and latitude on the phenology of the Spittle bug Neophilaenus lineatus . Funct. Ecol. , 13, 65-73.

Fält-Nardmann, J.J.J., Tikkanen, O.-P., Ruohomäki, K., Otto, L.-F., Leinonen, R., Pöyry, J. et al. (2018). The recent northward expansion of Lymantria monacha in relation to realized changes in temperatures of different seasons. Forest Ecol. Manag., 427, 96-105.

Gompert, Z., Mandeville, E.G. \& Buerkle, C.A. (2017). Analysis of population genomic data from hybrid zones. Annu. Rev. Ecol Evol. Syst., 48, 207-229.

Grant, P.R. \& Grant, B.R. (1992). Hybridization of bird species.Science, 256,193-197. 
Grant, P.R. \& Grant, B.R. (1994). Phenotypic and genetic effects of hybridization in Darwin's finches. Evolution , 48, 297-316.

Grant, P.R. \& Grant, B.R. (2019). Hybridization increases population variation during adaptive radiation. PNAS , 12, 23216-23224.

Gutaker, R M., Weiß, C.L., Ellis, D., Anglin, N.L., Knapp, S., Fernández-Alonso, J.L. et al. (2019). The origin and adaptation of European potatoes reconstructed from historical genomes. Nat. Ecol. Evol. , 3, 1093-1101.

Hamilton, J.A. \& Aitken, S.N. (2013). Genetic and morphological structure of a spruce hybrid (Picea sitchensis x P. glauca) zone along a climatic gradient. Am. J. Bot. , 100, 1651-1662.

Hamilton, J.A. \& Miller, J.M. (2015). Adaptive introgression as a resource for management and genetic conservation in a changing climate. Conserv. Biol. , 30, 33-41.

Hansen, M.M., Ruzzante, D.E., Nielsen, E.E. \& Mensberg, K.-L.D. (2000). Microsatellite and mitochondrialDNA polymorphism reveals lif-history dependent interbreeding between hatchery and wild brown trout (Salmo trutta L.). Mol. Ecol. , 9, 583-594.

Hanski, I. (1999). Metapopulation ecology . Oxford University Press.

Hard, J.J., Bradshaw, W.E. \& Holzapfel, C.M. (1993). The genetic basis of photoperiodism and its evolutionary divergence among populations of the pitcher-plant mosquito, Wyeomyia smithii . Am. Nat. , 142, $457-473$.

Heide-Jørgensen, M.P., Laidre, K.L., Quakenbush, L.T. \& Citta, J.J. (2012). The Northwest Passage opens for bowhead whales. Biol. Lett. , 8, 270-273.

Hewitt, G.M. (1996). Some genetic consequences of ice ages, and their role in divergence and speciation. Biol. J. Linn. Soc. , 58, 247-276.

Hewitt, G.M. (2000). The genetic legacy of the Quaternary ice ages.Nature , 405, 907-913.

Hewitt, G.M. (2001). Speciation, hybrid zones and phylogeography - or seeing genes in space and time. Mol. Ecol. , 10, 537-549.

Hewitt, G.M. (2004). Genetic consequences of climatic oscillations in the Quarternary. Phil. Trans. R. Soc. Lond. B , 359, 183-195.

Hewitt, G.M. (2011). Quarternary phylogeography: the roots of hybrid zones. Genetics , 139, 617-638.

Hulme, P.E. (2009). Trade, transport and trouble: managing invasive species pathways in an era of globalization. J. Appl. Ecol. , 46, 10-18.

Hultén, E. (1971). The circumpolar plants. II. Dicotyledons. Kungl. Svenska Vetenskapsakademiens Handlingar, Fjärde Serien, Band 13 (1). Almquist and Wiksell, Stockholm.

Jenkin, T.J. (1955). Interspecific and intergeneric hybrids in herbage grasses, XV. The breeding affinities of Festuca rubra . J Genet., 53, 125-130.

Jin, H., Jönsson, A.M., Olsson, C., Lindström, J., Jönsson, P. \& Eklundh, L. (2019). New satellite-based estimates show significant trends in spring phenology and complex sensitivities to temperature and precipitation at northern European latitudes. Int. J. Biometeorol. , 63, 763-775.

Johnsson, H. (1949). Studies on birch species hybrids. I. Betula verrucosa x B. japonica, B. verrucosa x B. papyrifera and B. pubescens X B. papyrifera.Hereditas , 35, 115-135.

Jonsell, B. ed. (2000). Flora Nordica, vol. 1. The Bergius Foundation, The Royal Swedish Academy of Sciences, Stockholm. 
Jordan, C.Y., Lohse, K., Turner, F., Thomson, M, Gharbi, K. \& Ennos, R.A. (2018) Maintaining their genetic distance: Little evidence for introgression between widely hybridizing species of Geum with contrasting mating systems. Mole. Ecol. , 27, 1214-1228. Https://doi.org/10.1111/mec.14426.

Kearney, M. (2005). Hybridization, glaciation and geographical parthenogenesis. TREE , 20, 495-502.

Keinänen, M., Julkunen-Tiitto, R., Rousi, M., \& Tahvanainen, J. (1999). Taxonomic implications of phenolic variation in leaves of birch (Betula L.) species. Biochem. Syst. Ecol. , 27, 243-254.

Kelly, B.P, Whiteley, A. \& Tallmon, D. (2010). The Arctic melting pot.Nature , 468, 891.

Kleindorfen, S., O'Connor, J.A., Dudaniec, R.Y., Myers, S.A., Robertson, J. \& Sulloway, F.J. (2014). Species collapse via hybridization in Darwin's tree finches. Am. Nat. , 183, 325-341.

Körner, C. \& Basler, D. (2010). Phenology under global warming.Science , 327, 1461-1462.

Lamichhane, S., Han, F., Webster, M.T., Andersson, L., Grant, B.R. \& Grant, P.R. (2018). Rapid hybrid speciation in Darwin's finches.Science, 359, 224-228.

Larson, E.L., Tinghitella, R.M. \& Taylor, S.A. (2019). Insect hybridization and climate change. Front. Ecol. Evol. , 7, 348 .

Levin, D.A. (1978). The origin of isolating mechanisms in flowering plants. Evol. Biol., 11, 185-317.

Maeda, E.E., Lisboa, F., Kaikkonen, L., Kallio, K., Koponen, S., Brotas, V. et al. (2019). Temporal patterns of phytoplankton phenology across high latitude lakes unveiled by long-term time series of satellite data. Remote Sens. Environ. , 221, 609-620.

Mallet, J. (2005). Hybridization as an invasion of the genome.TREE , 20, 229-237.

Mallet, J. (2007). Hybrid speciation. Nature , 446, 279-283.

Mallet, J., Besansky, N. \& Hahn, M.W. (2015). How reticulated are species? Bioessays , 38, 140-149.

Marcussen, T., Sandve, S.R., Heier, L., Spannagl, M., Pfeifer, M., The International Wheat Genome Sequencing Consortium, et al. (2014). Ancient hybridizations among the ancestral genomes of bread wheat.Science , 345, 1250092.

The Marie Curie SPECIATION Network (2012). What do we need to know about speciation? TREE , 27, $27-39$.

Markgraf-Dannenberg, I. (1980). Gen. Festuca. In: Flora Europaea 5. , Editors Tutin T.G., Heywood V.H., Burges N.A., Moore D.M., Valentine DH. London: Cambridge University Press, p. 125-153.

Marques, D.A., Meier, J.I. \& Seehausen, O. (2019). A combinatorial view on speciation and adaptive radiation. TREE, 34, 531-544.

McFarlane, S.E. \& Pemberton, J.M. (2019). Detecting the true extent of introgression during anthropogenic hybridization. TREE , 34, 315-326.

Menzel, A., Sparks, T.H., Estrella, N., Koch, E., Aasa, A., Ahas, R.,et al. (2006). European phenological response to climate changematches the warming pattern. Glob. Change Biol. , 12, 1969-1976.

Miralles, L., Oremus, M., Silva, M.A., Planes, S. \& Garcia-Vazquez, E. (2016). Interspecific hybridization in pilot whales and asymmetric genetic introgression in northern Globicephala melas under the scenario of global warming. PLosONE , 11, e0160080.

Morrow, P.A. \& Fox, L.R. (1989). Estimates of pre-settlement insect damage in Australian and North American forest. Ecology , 70, 1055-1060.

Nelson, R J., Denlinger, D.L. \& Somers, D.E. (2010).Photoperiodism, the Biological Calendar . Oxford Univ. Press. 
Niehaus, A.C. \& Ydenberg, R.C. (2006). Ecological factors associated with the breeding and migratory phenology of high-latitude breeding western sandpipers. Polar Biol ., 30, 11-17.

Nussey, D.H., Postma, E., Gienapp, P., \& Visser, M.E. (2005). Selection on heritable phenotypic plasticity in a wild bird population.Science, $310,304-306$.

Oja, H. \& Pöysä, H. (2007). Spring phenology, latitude, and the timing of breeding in two migratory ducks: implications of climate change impacts. Ann. Zool. Fennici , 44, 475-485.

Ottenburghs, J. (2019). Multispecies hybridization in birds. Avian Res. , 10, 20.

Palme, A.E., Su, Q., Palsson, S. \& Lascoux, M. (2004). Extensive sharing of chloroplast haplotypes among European birches indicates hybridization among Betula pendula, B. pubescens and B. nana . Mol. Ecol. , $13,167-178$.

Parmesan, C. \& Yohe, G. (2003). A globally coherent fingerprint of climate change impacts across natural systems. Nature , 421, 37-42.

Past Interglacials Working Group of PAGES. (2016). Interglacials of the last 800,000 years. Rev. Geophys. , $54,162-219$.

Payne, R.H., Child, A.R. \& Forrest, A. (1972). The existence of natural hybrids between the European trout and the Atlantic salmon. J. Fish Biol. , 4, 233-236.

Perino A., Pereira, H.M., Navarro, L.M., Fernández, N., Bullock, J.M., Ceaușu, S. et al. (2019). Rewilding complex ecosystems.Science, 364, eaav5570.

Polvani, L.M., Previdi, M., England, M.R., Chiodo, G. \& Smith, K.L. (2020). Substantial twentieth-century Arctic warming caused by ozone-depleting substances. Nat. Clim. Chang. , 10, 130-133.

Razgour, O., Forester, B., Taggart, J.B., Bekaert, M., Juste, J., Ibáñez, C. et al. (2019). Considering adaptive genetic variation in climate change vulnerability assessment reduces species range loss projections. PNAS , 116, 10418-10423.

Réale, D., Berteaux, D., McAdam, A.G. \& Boutin, S. (2003). Lifetime selection on heritable life-history traits in a natural population of red squirrels. Evolution , 57, 2416-2423.

Remington, C. (1968). Suture-zones of hybrid interaction between recently joined biotas. Evol. Biol. , 2, $321-428$.

Rhymer, J.M. \& Simberloff, D. (1996). Extinction by hybridization and introgression. Annu. Rev. Ecol. Syst. , 27, 83-109.

Richardson, D.M. \& Rejmánek, M. (2011). Tree and shrubs as invasive alien species - a global review. Divers. Distrib. , 17, 788-809.

Saikkonen, K., Dirihan, S., Väre, H., Saloniemi, I., Cräutlein, M., Leinonen, P.H. et al. (2019). Phenotypic and genetic variation in natural populations of Festuca rubra s. l. in Europe. Plant Ecol. Divers. , 12, 441-456.

Saikkonen, K., Taulavuori, K., Hyvönen, T., Gundel, P.E., Hamilton, C.E., Vänninen, I. et al. (2012). Climate change-driven species' range shifts filtered by photoperiodism. Nat. Clim. Chang. , 2, 239-242.

Sakai, A. \& Larcher, W. (1987). Frost Survival in Plants: Responses and Adaptation to Freezing Stress . Springer-Verlag.

Sala, O.E., Chapin III, F.S., Armesto, J.J., Berlow, E., Bloomfield, J., Dirzo, R. et al. (2000). Global biodiversity scenarios for the year 2100. Science, 287, 1770-1774.

Sánchez-Bayo, F. \& Wyckhuys, K.A.G. (2019). Worldwide decline of the entomofauna: a review of its drivers. Biol. Concerv. , 232, 8-27. 
Schmidt, P.S., Matzkin, L.M., Ippolity, M. \& Eanes, W.F. (2005). Geographic variation in diapause incidence, life-history traits, and climatic adaptation in Drosophila melanogaster . Evolution , 59, 2616-2625.

Schumann, G.L. (1998) Plant Diseases: Their Biology and Social Impact . APS Press.

Scriber, K.T., Page, K.S. \& Bartron, M.L. (2001). Hybridization in freshwater fishes: a review of case studies and cytonuclear methods of biological inference. Rev. Fish Biol. Fisher. , 10, 293-323.

Simpson, G.G. \& Dean, C. (2002). Arabidopsis, the Rosetta stone of flowering time? Science , 296, 285-289.

Soltis, P.S. \& Soltis, D.E. (2009). The role of hybridization in plant speciation. Annu. Rev. Plant. Biol., 60, 561-588.

Stearns, S.C. (1992). The evolution of life histories . Oxford University Press, New York, USA.

Tauber, E., Zordan, M., Sandrelli, F., Pegoraro, M., Osterwalder, N., Breda, C. et al. (2007). Natural selection favors a newly derived timeless allele in Drosophila melanogaster . Science , 316, 1895-1898.

Taulavuori, K., Taulavuori, E., Saravesi, K., Jylänki, T., Kainulainen, A., Pajala, J. et al. (2017). Competitive success of southern populations of Betula pendula and Sorbus aucuparia under simulated southern climate experiment in the subarctic. Ecol. Evol. , 7, 4507-4517.

Taylor, S.A., Larson, E.L. \& Harrison, R.G. (2015). Hybrid zones: windows on climate change. TREE , 30, 398-406.

Tewksbury, J.J., Sheldon, K.S. \& Ettinger, A.K. (2011). Moving farther and faster. Nat. Clim. Chang., 1, 396-397.

Thackeray, C.W., \& Hall, A. (2019). An emergent constraint on future Arctic sea-ice albedo feedback. Nat. Clim. Chang., 9, 972-978.

Thuiller, W., Lavorel, S., Araújo, M.B., Sykes, M.T. \& Prentice, I.C. (2005). Climate change threats to plant diversity in Europe. Proc. Natl Acad. Sci. USA , 102, 8245-8250.

Tsuda, Y., Semerikov, V., Sebastiani, F., Verdramin, G.G. \& Lascoux, M. (2017). Multispecies genetic structure and hybridization in theBetula genus across Eurasia. Mol. Ecol. , 26, 589-605.

van Kleunen, M., Dawson, W., Essl, F., Pergl, J., Winter, M., Weber, E., et al. (2015). Global exchange and accumulation of non-native plants. Nature , 525, 100+.

Walter, G.-R., Roques, A., Hulme, P.E., Sykes, M.T., Pyšek, P., Kúhn, I.et al. (2009). Alien species in a warmer world: risks and opportunities. TREE , 24, 686-693.

Warren, B.H., Simberloff, D., Ricklefs, R.E., Aguilée, R., Condamine, F.L., Gravel, D. et al. (2015). Islands as model systems in ecology and evolution: prospects fifty years after MacArthur-Wilson.Ecol. Lett. , 18, 200-217.

Weir, J.T. \& Schluter, D. (2004). Ice sheet promote speciation in boreal birds. Proc. R. Soc. Lond. B . 271, 1881-1887.

Whitham, T.G. (1989). Plant hybrid zones as sinks for pests.Science 244, 1490-1493.

Wilson, E.O. (1988). Bioidiversity . National Academy Press, Washington, DC, USA.

Xiang, Q.-P., Wei, R., Shao, Y.-Z., Yang, Z.-Y., Wang, X.-Q. \& Zhang, X.-C. (2015). Phylogenetic relationships, possible ancient hybridization, and biogeographic history of Abies (Pinaceae) based on data from nuclear, plastid, and mitochondrial genomes. Mol. Phylogenet. Evol. 82, 1-14.

Zeng, H., Jia, G. \& Epstein, H. (2011). Recent changes in phenology over the northern high latitudes detected from multi-satellite data.Environ. Res. Lett. , 6, 045508. 
Zhao, J., Zhang, H., Zhang, Z., Guo, X., Li, X. \& Chen, C. (2015). Spatial and temporal changes in vegetation phenology at middle and high latitudes of the northern hemisphere over the past three decades.Remote Sens. , 7, 10973-10995.

\section{Time window for reproduction}

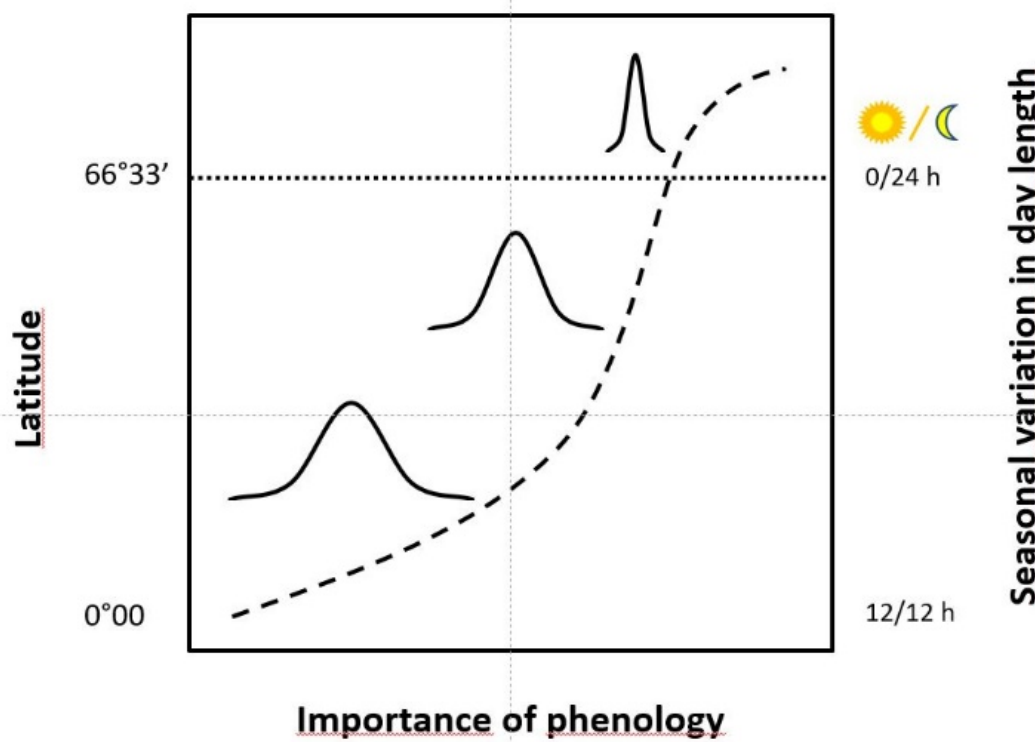

Figure. 1. The effects of latitude and the seasonality of day length on phenology and the time window for successful reproduction.

a)

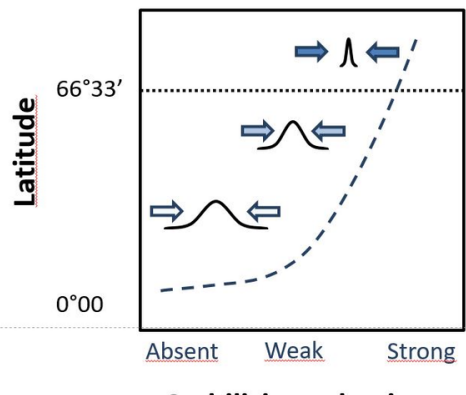

Stabilizing selection b)

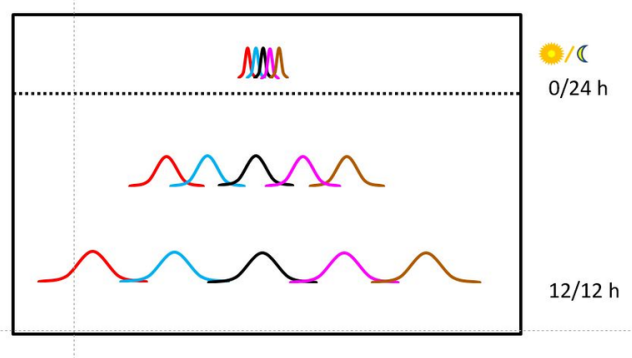

Timing of reproduction

Figure. 2. Latitude-driven (a) stabilizing selection on light-dependent traits and (b) the timing of reproduction. Different colours in Figure b indicate genetically distinct populations or species. 
a)

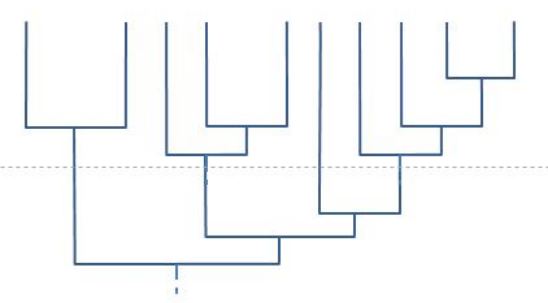

b)

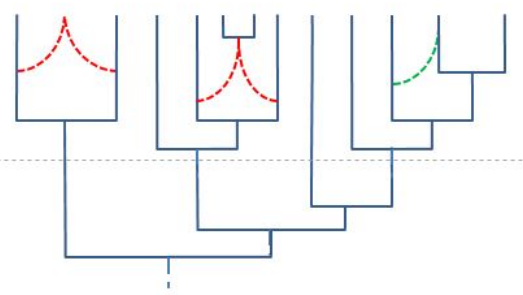

Figure. 3. Bifurcating phylogenetic tree (a) and phylogenetic network with genotypic clusters (b). Hybrid speciation and introgression between lineages are indicated in red and green, respectively.
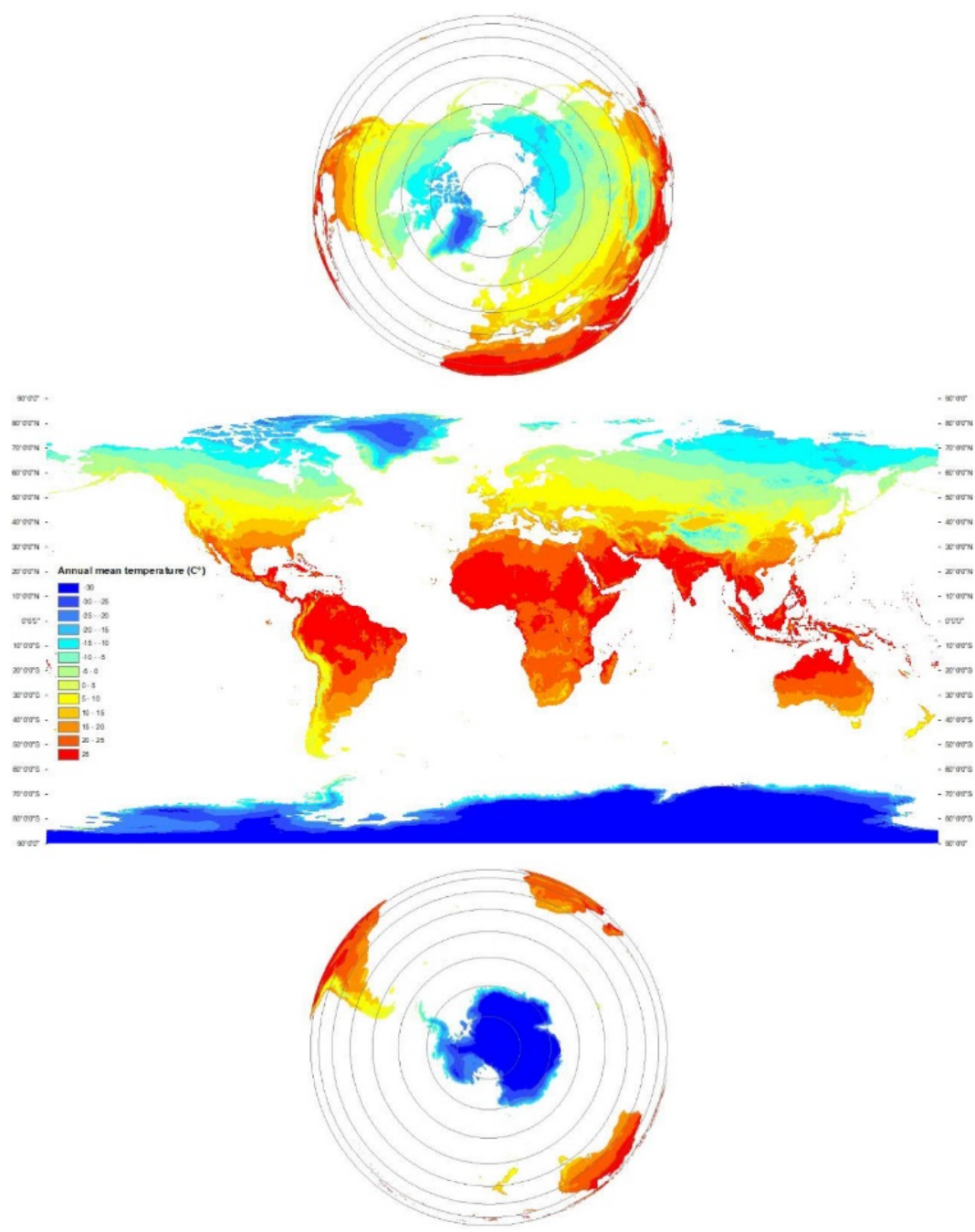

Figure. 4. World climate map demonstrating that the distributions of land and sea of the polar regions are geographically almost the opposite, and comparable climate zones are present at higher latitudes in Western Europe compared with those in North America and Russia. Data taken from the WorldClim Database (http://www.worldclim.org/). 


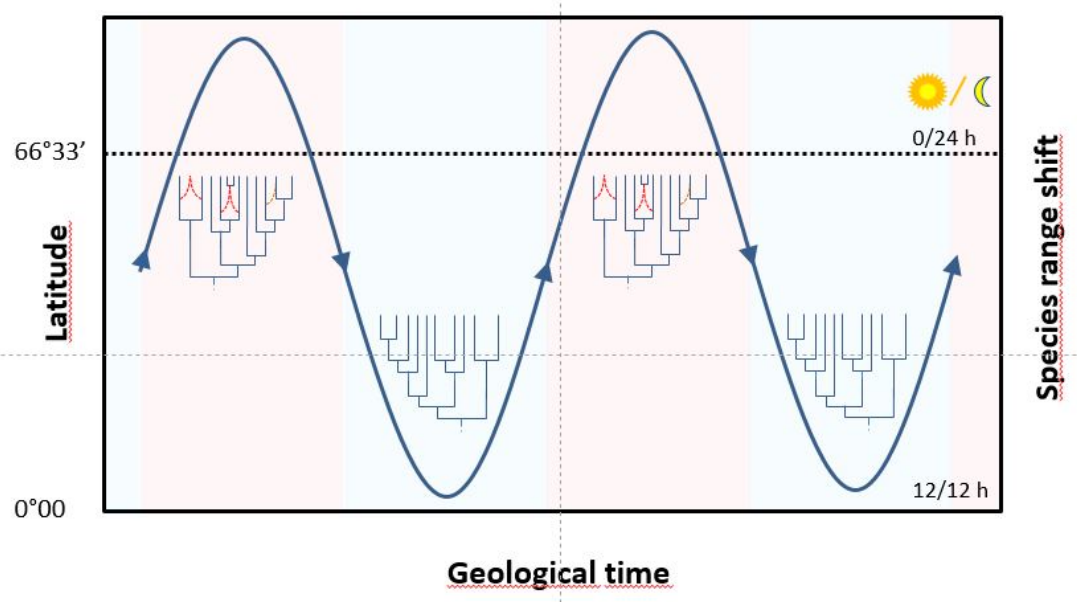

Figure. 5. Species' range shifts across latitudes with different light environments during the cycles of Earth's cooler and warmer periods in geological time. Phylogenetic trees indicate the relative importance of introgressive hybridization vs. bifurcating speciation (Fig. 3) in adaptive divergence. 